
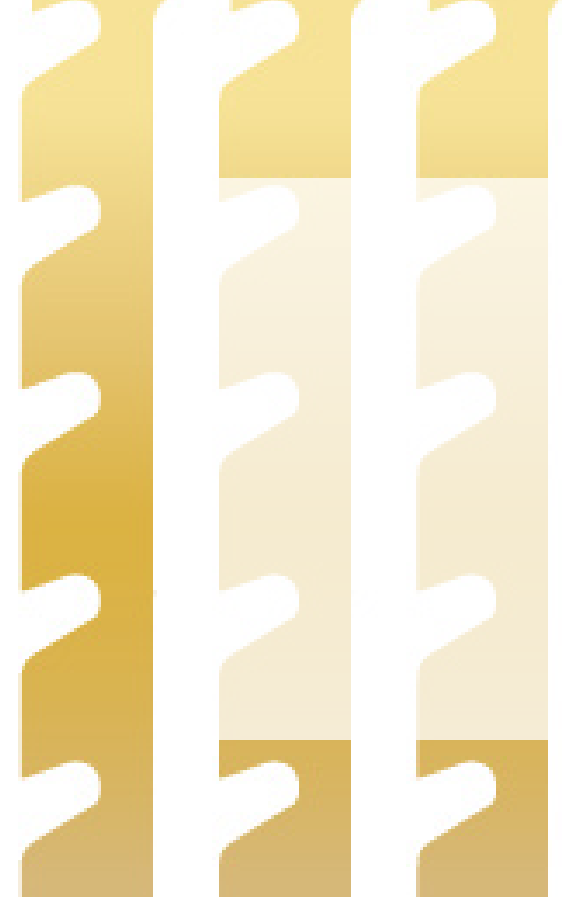

\title{
Medicalização e Subjetividade
}
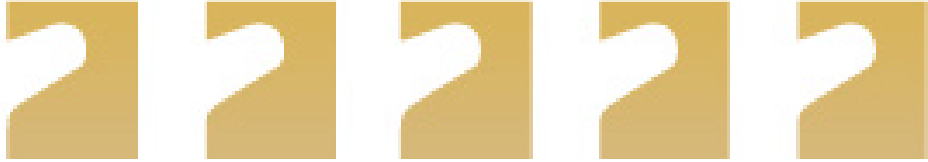

\section{Luciano Elia*}

O tema da Mesa, Medicalização Subjetividade, transmite sua crucialidade por si: é uma discussão absolutamente importante e fundamental e cumprimento os proponentes desta Mesa, meus anfitriões, e meus colegas de Mesa, por esta iniciativa. Escolhi abordar o tema por um viés que coloque em cena os fundamentos mesmos do cenário atual, marcado pela mais devastadora imposição da ideologia cientificista - que não considero digna do epíteto de científica posto que de ciência ela nada tenha - do domínio capitalista e neoliberal do qual Estado, ciência e sociedade são hoje os maiores lacaios e reféns, e que atrela a si as práticas mais desastrosas no campo da saúde mental, pautadas na miséria conceitual dos manuais diagnósticos e no afã mais voraz de medicar. A elas se associam retrocessos inimagináveis há apenas dez anos atrás (quando, aliás, ele se iniciou) nas políticas públicas de saúde mental. Resulta um cenário obscuro, que não vem se li-

Nota da organização: palestra proferida no Seminário de fundação do Observatório de Direitos Humanos e Justiça Criminal do Espírito Santo- ODHES, 2015 - Vitória

*Professor titular e coordenador do Programa de Mestrado Profissional em Psicanálise e Políticas Públicas do Instituto de Psicologia da Universidade Estadual do Rio de Janeiro (UERJ) 
mitando à medicalização, mas se alastra para a patologização crescente de problemáticas que em si mesmas nada têm de psicopatológicas, como o uso abusivo de drogas por populações jovens em grandes cidades, muitos em situação de rua (a ponto de falar-se em dependência química - numa versão mais psiquiátrica - ou mesmo de toxicomanias - numa vertente psicanalítica completamente equivocada - lá onde essas duas categorias seriam rigorosamente inaplicáveis), na judicialização dessas condições psicossociais e finalmente, abaixando suas verdadeiras cartas, na mais franca criminalização da pobreza.

Retomo o começo deste processo, numa perspectiva histórica que não posso deixar de considerar, tendo em vista o percurso que quero fazer aqui.

A Reforma Psiquiátrica Brasileira e seu correlato movimento social intitulado Movimento da Luta Antimanicomial não são dissociáveis do contexto histórico-político no qual se originaram e no qual encontraram as condições de sua força: a ditadura militar brasileira. No contexto da ditadura, um movimento da área da Saúde - não da saúde mental, mas da saúde - precedeu a Reforma Psiquiátrica e pavimentou as vias de sua efetivação: foi a Reforma Sanitária Brasileira, aquela que criou o SUS - este mesmo que se encontra agora tão ameaçado em suas bases, e que é um dos melhores sistemas de saúde do mundo, caso funcionasse. A Reforma Sanitária constituiu uma grande trincheira política de resistência à ditadura. Pois bem, a Reforma Psiquiátrica Brasileira é tributária da Reforma Sanitária, e não teria sido como foi sem este antecedente histórico-político.

Do um ângulo diferente, especifico do campo da saúde mental e dos movimentos internacionais, diremos que a RPB inspirou-se muito mais na Psiquiatria Democrática Italiana, liderada por Franco Basaglia, do que em outros movimentos, como a Psiquiatria Comunitária anglo-americana e a Psiquiatria de Setor, francesa. A principal diferença está no princípio de que, no movimento italiano, trata-se de extinguir o manicômio daí o nome do movimento social "antimanicomial" - e não de 
humanizá-lo ou articulá-lo a uma rede comunitária e à cidade. Como pensador social crítico, marxista, e não apenas como psiquiatra social, Basaglia sabia muito bem que a humanização de uma prática não bastava para mudar a sua estrutura discursiva, coincidindo, nesta posição metodológico-política, e de modo inesperado, com uma posição discursiva que é própria à psicanálise.

Basaglia não gostava de psicanálise, e tinha suas razões para isso: a psicanálise sempre primou por uma posição elitista, a despeito de que, em seu discurso, nenhum elitismo é autorizado. A comunidade psicanalítica, suas práticas e posições teórico-políticas socialmente sustentadas não se colocavam ao lado das propostas de Basaglia, não lhe serviriam para nada, e ele não tinha como se aliar a elas. Além disso, sua tarefa política, conceitual e clínica urgia e ele não tinha tempo a perder. No entanto, em uma intervenção feita no Rio de Janeiro e publicada em livro, ele diz:

\begin{abstract}
"É complicado falar de Freud, mas podemos dizer que, frequentemente, as pessoas que tem um significado na história do homem são aquelas que determinam as tensões nas contradições. Eu acho que a humanidade sempre se dividiu em duas partes: os inventores e os contadores. Os contadores não fazem nada além de estudar as técnicas de quem inventou as leis das contradições. Provavelmente, os dois são necessários, porém, quando ambos estão presentes, o importante é que entrem em pura contradição. Isso já é uma esperança!"1
\end{abstract}

Para Basaglia, portanto, Freud é um homem cujo significado na história decorre de ele ter determinado tensões nas contradições. Freud está do lado dos inventores e não dos contadores e inventou as leis das contradições. Uma honrosa leitura dialética de Freud.

Nós, psicanalistas que tomamos a nós o desejo e a tarefa decidida de nos inserir no campo público da saúde mental, sa-

${ }^{1}$ BASAGLIA, F. - Psiquiatria alternativa: contra o pessimismo da razão, o otimismo da prática. São Paulo: Brasil Debates, 1979, p. 28. 
bemos que a psicanálise não coincide com o que sua prática tradicional representa, estamos em condições de verificar as impressionantes convergências entre o pensamento de Basaglia e o de Lacan, por exemplo, e, em última análise, entre Marx e Freud, suas respectivas fontes inspiradoras.

A Reforma Psiquiátrica Brasileira teve inspiração italiana e foi mais radical do que outras em sua incidência concreta antimanicomial: fechamento de hospitais e redução de leitos psiquiátricos, criação de redes substitutivas extremamente potentes e inventivas, invenção do campo da atenção psicossocial, genuinamente brasileira e que ultrapassa, em muito, as intenções que seus criadores tinham ao criá-la. Retomarei este campo adiante.

Em 2005, em uma reunião da Organização Pan-Americana da Saúde (OPAS) da qual participei em Brasília, e que comemorava os 15 anos da Carta de Caracas, constatamos, com alegria, que o Brasil, dos signatários da referida Carta de 1990, que pactuaram várias ações do Estado na saúde mental, foi o país que mais ações realizou. Outro fato importante da história recente do processo político da RPB é o de que o Brasil foi signatário de um acordo internacional de apoio à redução de danos, contrariando "velhos aliados" aqui influentes como Estados Unidos e Japão, no ano de 2002, ato que os últimos 13 anos não cessam de denegar e desmentir, em termos de nossas políticas de Estado em saúde mental.

Como se sabe, a Reforma Sanitária criou a noção de atenção à saúde, e estruturou três niveis de atenção á saúde: a primária ou básica, a secundária e a terciária. Não vou me deter aqui nesses niveis, que acredito que todos conheçam e que só menciono para deles diferenciar uma novidade que a Reforma Psiquiátrica criou, uma nova modalidade - e aqui peço toda a atenção: modalidade e não nível - de atenção: a ATENÇÃO PSICOSSOCIAL.

Os sanitaristas da época, os bons sanitaristas, pilotos da Reforma Sanitária Brasileira, não só não tinham em relação à Reforma psiquiátrica nenhuma espécie de reserva, antinomia ou 
conflito, como apoiaram vivamente a criação desta nova modalidade de atenção, a atenção psicossocial, sem sentirem-se ameaçados, como sanitaristas, de que a atenção psicossocial e a saúde mental fossem rivalizar com o campo estritamente sanitário, reduzi-lo ou relativizá-lo.

Na verdade, a saúde mental extravasa o campo da saúde, ela não é estritamente um recorte do campo da saúde. Saúde mental não é estritamente saúde. O mental da expressão, mais do que um adjetivo restritivo, precisa ser tomado em sua dimensão significante (o que afasta o empuxo de fazer dele o signo do que se refere à mente), metaforizando o sentido da expressão, com o que ultrapassa a lógica saúde/doença, mesmo na perspectiva de "promoção e da prevenção à saúde", que veio depois a tomar a dianteira, numa tentativa de re-sanitarizar o campo da saúde mental por um viés

Mas os sanitaristas que estavam na proa do movimento da Reforma Sanitária Brasileira, e aqui cito Sergio Arouca, Ligia Bahia, e Gastão Wagner, entre outros, não tinham nenhuma preocupação com essa vocação extravasante da saúde mental em relação ao campo da saúde. O que lhes permitia isso, senão sua posição política, mas também conceitual e práxica, orientada pelos princípios marxistas? Desde que se é um marxista (como Basaglia), a questão da saúde já começou a extrapolar os limites sanitários, posto que a dialética das contradições e das relações sociais de conflito estão, de saída, postas em jogo. Nenhum sanitarista-marxista defenderá protocolos de ação de cuidado meramente tecnicistas, operacionais, formais - para não dizermos burocráticos, orientados pelo atendimento a metas de produtividade, "eficácia", otimização de recursos, "simplificação do cuidado" e outras pérolas do jargão atualmente em proa no campo do sanitarismo neoliberal e das práticas gerenciais da gestão pública, que, mais do que promoverem a privatização pela delegação do exercício e do poder gestor a entidades privadas propriamente ditas, as famosas OSs que se reproduzem como coelhos no Brasil, tornam-se o próprio estado o ícone do mundo privado, pelo empresariamento do próprio Estado. Por quê? Porque um sanitarista-marxista segue princípios e não procedimentos, con- 
cebe as relações sociais de forma dialética e não tecnocrata, e tem sempre claro para si que a dimensão social não abandona jamais a problemática de saúde, e mais ainda na área de saúde mental, em que, de saída, o sofrimento decorre de uma complexa trama de fatores muito além do funcionamento de um organismo biológico. Daí a famosa frase de Basaglia: "todo sofrimento é sofrimento em relação ao corpo social" - e não ao corpo orgânico.

A leitura que faço desta convergência entre os sanitaristas que pilotaram a Reforma Sanitária e criaram o SUS e os operadores da Reforma Psiquiátrica é que os princípios político-ideológicos que regiam a práxis desses sanitaristas, por serem princípios de saúde coletiva, e por sua inspiração socialista, eram os mesmos que regiam a atenção psicossocial. E por isso não thes era dificil admitir que esta modalidade de atenção não coubesse, como, aliás, não cabe nem pode caber, e esta é uma das posições que quero defender aqui, nos níveis de atenção em saúde. Não é possível sanitarizar demasiadamente a saúde mental, porque todo aquele que algum dia veio a se relacionar com a loucura sabe que ela não cabe na saúde, ela não cabe na medicina, e é por isso, como diz Edmar de Oliveira, psiquiatra de posição crítica e vanguarda na reforma psiquiátrica brasileira, que a psiquiatria, a boa psiquiatria, expeliu-se a si mesma da medicina, constituindo a primeira "especialidade médica" sem ser, de forma alguma, uma especialidade médica, a rigor. E penso também que é por isso que um Karl Jaspers, psiquiatra dos grandes, dos tempos em que a clínica psiquiátrica era uma prática experiencialmente rica, foi levado a criar, na epistemologia (ele se tornou epistemólogo por força de seu encontro com a loucura, penso eu) a dualidade entre ciências da natureza e ciências da cultura: a loucura o obrigou a isso, já que ela não cabe em uma só dessas bandas científicas, exige as duas.

Mas o ponto mais subversivo da atenção psicossocial é a sua potência em afetar o tecido social. A prática dos CAPS, muito além da intersetorialidade que já a retira do espaço intramuros da saúde e da territorialidade que a lança no espaço das instâncias formais e informais da cidade, consiste em uma in- 
cisiva e ao mesmo tempo delicada (no mesmo sentido de uma cirurgia em um tumor recôndito em alguma porção interna e pouco acessível do cérebro) intervenção e afecção no tecido social. Uma clínica-política do tecido social, e neste binômio (clínica-política), o termo política não deve ser tomado como adjetivo em relação ao termo clínica, e sim como um segundo substantivo: trata-se de uma clínica que é ao mesmo tempo uma política. Não apenas aquele cujo psiquismo sofre "grave e persistentemente", mas os que convivem com ele, parentes, vizinhos, parceiros de laços sociais, quando existem, e também os profissionais que dele tratam a diferentes títulos, precisam entrar, por assim dizer, em uma nova lógica, na qual o mote principal é que se suporte a loucura no laço social que tem por função contumaz e histórica rechaçá-la, segregá-la, interná-la, excluí-la. Não é fácil que uma sociedade, um Estado, uma gestão pública suportem uma coisa como o CAPS, quando ele opera próximo à plenitude de sua potência!

Pois bem, a atenção psicossocial jamais foi, em seus princípios (e em seu princípio, seus tempos heroicos) uma prática exclusivamente sanitária, de cuidado restritivo em saúde. Agenciada pela saúde, ela convoca outros setores - a assistência social, a educação, a justiça, e todos os demais setores e instâncias, formais e informais, que se perfilarem no território, noção de nosso grande Milton Santos que pode ser conceituada como o lugar psicossocial do sujeito. Seus princípios são tão amplos quanto os do SUS - acessibilidade, acolhimento universal, integralidade do cuidado - e nisso ela converge com a atenção básica, com a qual, contudo, ela não pode concorrer em termos da abrangência social, do financiamento, da democratização e acesso ao cuidado. É preciso manter a atenção psicossocial em sua especificidade, que se especifica por não ser afeita a nenhuma especialidade: todos os profissionais, todos os atores, todos os agentes podem e devem intervir na ação e cuidado, na ação clínica, que é política ao mesmo tempo, pois que sempre visa a posição do sujeito em relação ao corpo social concreto, ao laço social, à cidade e à cidadania. O que aconteceu nas políticas públicas, quando este campo, o da atenção psicossocial, encontrava-se em plena expansão no Brasil - e, particularmente no Rio de Janeiro, a única cidade 
que entendia que CAPS era um tipo de dispositivo crucial que exigia supervisão clínico-territorial (não supervisão que se limita ao caso clínico e à relação terapêutica interindividual, mas supervisão que garante a articulação entre a clínica do território e a política da cidade)? Na rede de CAPS do Rio de Janeiro, todo CAPS tinha um supervisor assim, não um funcionário da gestão, subordinado administrativamente a ela, mas um parceiro que mantinha, em relação à equipe e à gestão, uma importante exterioridade, uma certa tensão política, algo avançado demais para uma gestão não avançada suportar.

E a gestão não suportou mesmo não. Mas não apenas por razões internas, do Rio, e é por isso que escolhi um viés nacional. O governo de FHC operou uma reforma do estado, de caráter neoliberal, que fez com que os DIREITOS SOCIAIS tenham-se transformado em SERVIÇOS SOCIAIS. ISSo os insere no mercado e na lógica do capital, e se o Estado passa a ser um prestador de serviços em vez de um assegurador de direitos, a via para a privatização está aberta: se o estado presta serviços, qualquer entidade pode prestá-lo, e a porteira se abriu para o que vieram a ser as atuais OSs. A política de recursos humanos mudou, fragilizando e desestabilizando os vínculos que o funcionalismo público, quando engajado na causa e nos princípios da reforma, como ele era, preservava; os gestores tornaram-se autoritários; as pactuações coletivas desapareceram; os funcionários são contratados e demitidos pelas OSs a seu critério, quando tornam-se críticos ou fogem aos padrões estabelecidos; os princípios foram destruídos e substituídos por protocolos, metas, procedimentos; a ideia de rede, que era real quando articulada pela atenção psicossocial, passou a ser burocratizada quando inventaram a RAPS, que tem rede como inicial da sigla mas que na verdade é a morte da rede real, pois a transforma em uma trama de dispositivos protocolares, esses que se apresentam muito bem em datashow mas não operam no real do território.

O CAPS, em seu princípio, não é um serviço de saúde mental entre outros, mas uma lógica territorial de atenção, o polo de encarnação no território de uma política e de uma lógica de cuidado articulado em rede. Não é, portanto, concebivel que o CAPS não seja, ele próprio, uma instância em rede. Ele é 
como uma aranha que retira de seu próprio ventre os fios que tecem a teia em torno dele, e esta teia é uma rede viva. Se ele for tomado como um ponto desta teia, entre outros, estaremos colocando uma cinta em torno de cada um, impedindo que eles formem teias e se tornem serviços especializados em casos graves, por exemplo. Ele assim não poderá mais expelir esses fios, formar sua teia-rede, e uma rede artificial, morta, de nylon, será jogada sobre vários pontos assim concebidos e entupidos, fazendo crer que existe uma rede quando ela de fato não existe. É isso que faz a RAPS (Rede De Atenção Psicossocial), que define o CAPS como serviço especializado e faz entrecruzamento protocolar e artificioso de várias redes, a RUE (Rede de Urgência e Emergência), por exemplo, que se encarregaria das urgências e emergências.

Pelo viés de um suposto combate ao uso abusivo de drogas, as forças conservadoras da sociedade, assimiladas pelos gestores públicos em nível nacional (a começar pela presidência da República, que, na era Dilma, recrudesceu o processo de judicialização, criminalização e recolhimento dos usuários através das comunidades terapêuticas e das internações compulsórias, e pela transferência da SENAD (Secretaria Nacional de Políticas Sobre Drogas) para o Ministério da Justiça, ganharam significativa parcela do terreno que, em relação à loucura, a Reforma e a Luta Antimanicomial haviam conquistado.

E, finalmente, a atenção básica fagocitou a atenção psicossocial, a subsumiu. Todo cuidado é pouco em relação a isso, pois as pessoas de má fé sempre interpretam essa minha colocação como uma crítica à atenção básica, o que é, para dizer o mínimo, uma interpretação indecente. Sou o mais fervoroso partidário da atenção básica e, quando me referi aos sanitaristas de boa cepa, os de inspiração socialista, os que promoveram a Reforma Sanitária, criaram o SUS, a categoria de atenção à saúde e, portanto a atenção básica como a base democrática da pirâmide da saúde, sem com isso rivalizarem por um só instante com a atenção psicossocial que eles próprios ajudaram a parir, eu estava exatamente invocando uma identidade de princípios conceituais, éticos e ideológicos, mais do que uma submissão de um campo ao outro, isto é, a submissão da dimensão psicossocial, excedente da saúde, 
cultural, social, subjetiva, ao campo medicalizado, modelado e disciplinarizado de um sanitarismo ortopédico.

O "sanitarismo" atual (se é que podemos chamá-lo assim, com tão nobre denominação) nada tem a ver com os princípios éticos das nossas duas reformas, a sanitária e a psiquiátrica, e na verdade não tem princípios senão o do poder e da lógica neoliberal, na qual se inscreve a chamada "atenção básica" de hoje em dia, privatizada, eminentemente medicalizante, tecnicista, burocrática, protocolar, e que extingue qualquer espaço para o sujeito, seja o sujeito histórico, o sujeito social, seja o sujeito do inconsciente, o sujeito da palavra e da linguagem, duas vertentes de uma política pública verdadeiramente transformadora do cenário social de sofrimento, de exclusão e de segregação.

Bem, este é o cenário obscuro da política pública de saúde mental da cidade do Rio de Janeiro, que desafortunadamente não é diferente da política pública de saúde mental de todo o Brasil. 